\title{
Digestive tract hemorrhage due to complications with gastrointestinal stromal tumor treated with sunitinib: A case report
}

\author{
YAN LIU $^{1}$, HE-LONG ZHANG ${ }^{2}$, YE ZHANG ${ }^{3}$, JIA-ZHUAN MEI ${ }^{1}$, HONG-WEI LIN $^{1}$, YAN-WEI GUO ${ }^{1}$, \\ RUI-JUN LI ${ }^{1}$, XIANG-RUI MENG ${ }^{1}$, GUI-JU LIU ${ }^{1}$, MIN LI $^{1}$, PENG XIAO $^{1}$ and HUA BAI ${ }^{1}$ \\ ${ }^{1}$ Department of Oncology, Zhengzhou People's Hospital, Southern Medical University, Zhengzhou, Henan 450003; \\ ${ }^{2}$ Department of Oncology; ${ }^{3}$ Center of Diagnosis and Treatment for Infectious Diseases, Tangdu Hospital, \\ Fourth Military Medical University, Xi'an, Shaanxi 710038, P.R. China
}

Received July 12, 2012; Accepted October 11, 2012

DOI: $10.3892 / \mathrm{ol} .2012 .1050$

\begin{abstract}
Gastrointestinal stromal tumors (GISTs) are rare, and account for $1 \%$ of all gastrointestinal neoplasms. GISTs are the most frequent mesenchymal tumors of the gastrointestinal tract. However, the clinical and pathological characteristics of these neoplasms are not adequately understood. The best treatment approach for GISTs remains unclear. In the present study, we report a case of a GIST originating from the stomach. A digestive tract hemorrhage occurred as a complication of sunitinib treatment. This is the first report of a digestive tract hemorrhage due to sunitinib treatment.
\end{abstract}

\section{Introduction}

Gastrointestinal stromal tumors (GISTs) are a type of cancer that develops in supportive or connective tissues of the digestive system (1). The disease generally affects adults aged 50-70 years, but gender predilection is unclear. The most frequent site of occurrence is the stomach (60\% of cases), followed by the small bowel (35\%) and other sites (colon, rectum and esophagus; $<5 \%$ ) (2). They primarily arise from mesenchymal tumors of the gastrointestinal tract. Previous evidence demonstrated that most GISTs originate from Cajal pacemaker cells; however, the presence of receptors in omental, mesentery and uterine tumors has raised doubts about the exclusivity of their origin from pacemaker cells (3-5). GISTs express the cell surface transmembrane receptor KIT, which leads to uncontrolled cell proliferation and resistance to apoptosis upon activation (6-9). Tumor resection is one option for treating the localized disease, but recurrence is common.

Correspondence to: Professor Jia-Zhuan Mei, Department of Oncology, Zhengzhou People's Hospital, Southern Medical University, 33 Huanghe Road, Jin Shui District, Zhengzhou, Henan 450003, P.R. China

E-mail: mjzhuan@163.com

Key words: gastrointestinal stromal tumor, sunitinib, hemorrhage
Tyrosine kinase inhibitors (TKIs) such as imatinib and sunitinib are the standard therapy for metastatic or unresectable GISTs $(10,11)$. Usually, Response Evaluation Criteria in Solid Tumors (RECIST) combined with imaging data (CT scan and PET) are used to assess tumor response to treatment $(12,13)$.

\section{Case report}

An 80-year-old female underwent several examinations in August 2009 for a gall stone. A CT scan disclosed a gastric mass. The patient underwent a partial gastric resection in September 2009 (Fig. 1A). The tumor size was $7.5 \times 5 \mathrm{~cm}$, and the immunohistochemical analysis revealed the tumor was positive for CD117 (Fig. 1B), CD34 (Fig. 1C) and DOG-1 (Fig. 1D), but negative for S100. The patient started imatinib treatment at $400 \mathrm{mg} /$ day and was examined every three months (Fig. 2A and B). She remained well, and stopped imatinib treatment in March 2011. In June 2011, when the patient was referred to Zhengzhou People's Hospital, recurrence was documented in the gastric remnant (Fig. 2C and D). Beginning in July 2011, she was treated with sunitinib ( $37.5 \mathrm{mg} /$ day), but demonstrated poor tolerance. She experienced frequent lack of hunger, fatigue, somnolence, nausea and vomiting. In August 2011, she was hospitalized for fatigue. A CT scan presented reductions in the size of the gastric mass and enlarged lymph nodes (Fig. 2E and F). In August 2011, the patient began to exhibit hematemesis and was hospitalized. Later, she presented with digestive tract hemorrhage, and following this, melena and bloody stool occurred. On September 4, 2011, the patient's hemoglobin concentration was $102 \mathrm{~g} / 1$. By September 6, 2011, the hemoglobin concentration was down to $76 \mathrm{~g} / \mathrm{l}$. Therefore, conservative medical management was adopted. Hemorrhage stopped gradually. Although the patient experienced gastrointestinal bleeding complications, her treatment was effective. Thus, we suggested continuing sunitinib treatment at a reduced dose or participating in clinical trials of new drugs. The patient rejected these suggestions. She is currently receiving best supportive care (BSC), and follow-up is in progress. Written informed consent was obtained from the patient for publication of this case report and accompanying images. 

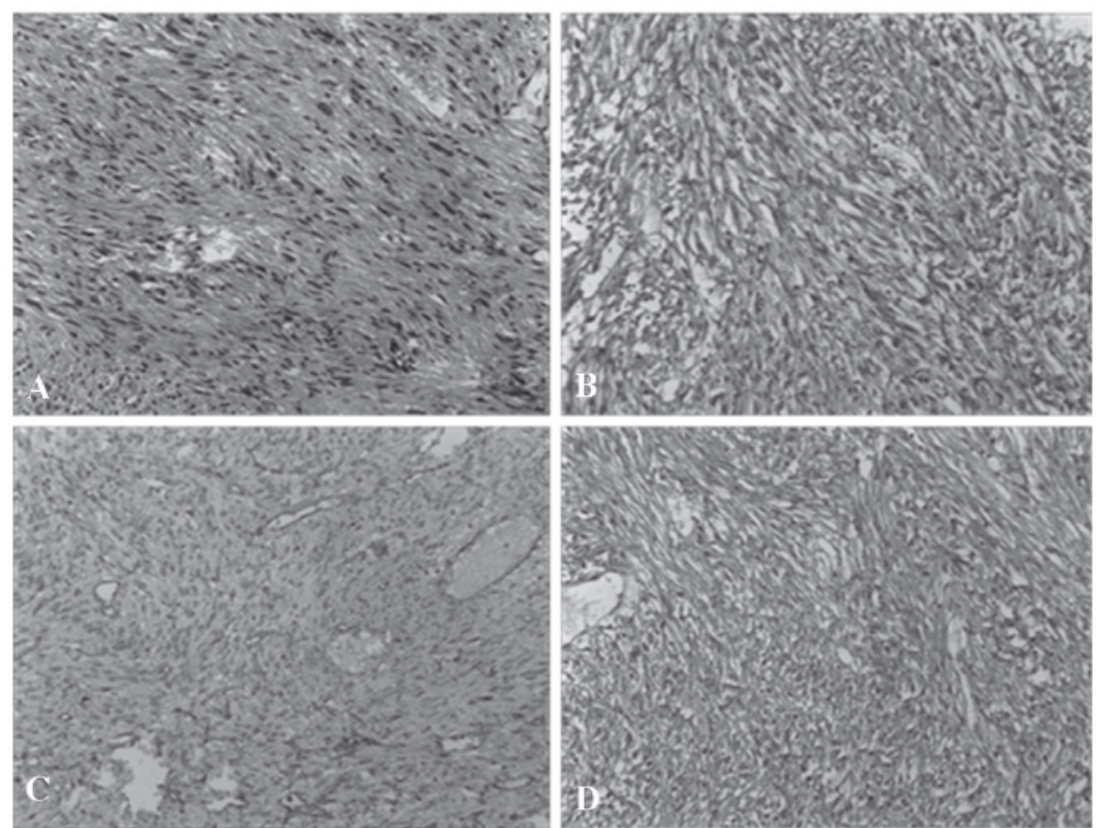

Figure 1. (A) Hematoxylin and eosin staining of gastrointestinal stromal tumors (GIST). The immunohistochemistry study of the GIST revealed positive results for CD117 (B), CD34 (C) and DOG-1 (D).
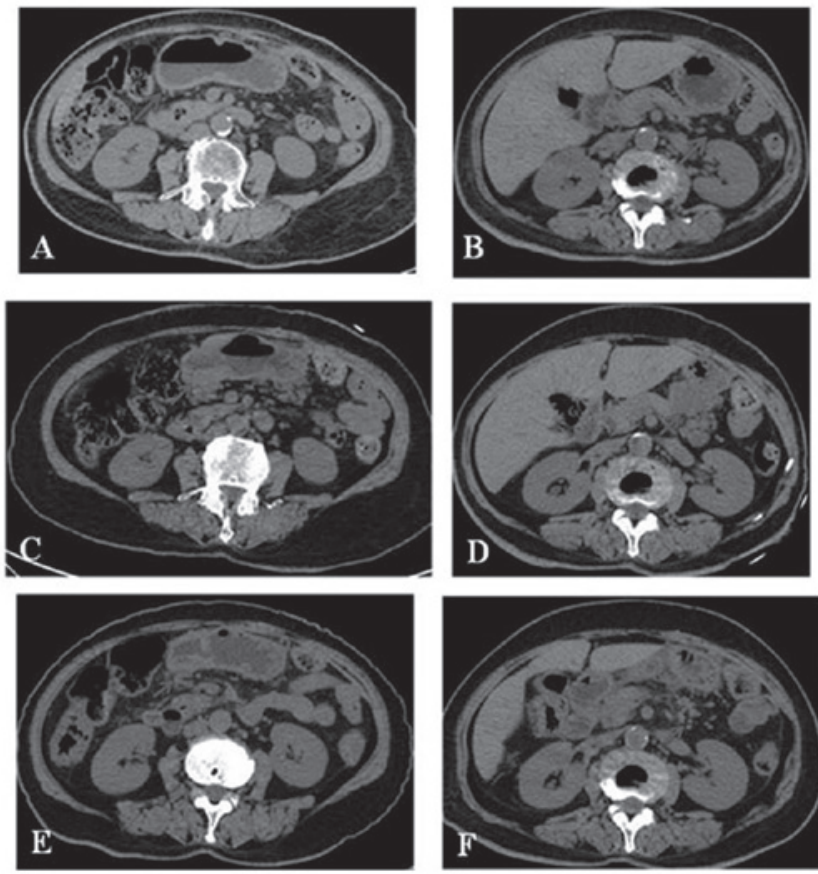

Figure 2. (A) Stomach CT following surgery. (B) CT demonstrated no lymph node metastasis in the abdominal cavity. (C) Stomach CT showed recurrence. (D) CT demonstrated lymph node metastasis in the abdominal cavity. (E) Stomach CT showed that the mass was reducing in size. (F) CT demonstrated that the abdominal cavity lymph node was reducing in size.

\section{Discussion}

Pathogenetic mechanisms of GISTs are poorly understood. KIT and PDGFRA mutations drive mesenchymal tumors, including GISTs (gastrointestinal tract sarcomas). Histologically, GISTs vary from spindled to epitheloid and mixed cell tumors. The pathological features are different according to different sites. Gastric GISTs appear as spindle cells and epitheloid cells, but most small intestinal GISTs are spindle cells. Mutations in KIT or PDGFRA lead to increased cellular proliferation and decreased apoptosis. Approximately 85\% of GISTs have mutations in KIT or PDGFRA (14-17). Tumors with kinase mutations in exon 11 or 9 have a higher overall response to therapy with receptor tyrosine kinase; therefore, these patients have a significantly longer overall survival.

GISTs are often presented with related symptoms such as anemia or mucosal ulcerations. The diagnostic evaluation is determined by pathological examination. KIT (CD117) is a transmembrane receptor which is a part of the tyrosine kinase receptor complex. GISTs are typically immunoreactive for KIT, thus the presence of CD117 confirms GIST diagnosis by immunohistochemistry. Approximately $90-100 \%$ of GISTs express CD117, and $70-80 \%$ are positive for CD34, which is the hematopoietic progenitor cell antigen $(3,18,19)$.

GISTs are not sensitive to conventional chemotherapy. The response rate to chemotherapy is $<10 \%$. However, targeted therapy has shown some promising results. Imatinib mesylate (a TKI) is considered to be the standard first-line agent in the treatment of unresectable or metastatic GISTs (20). Imatinib, formerly known as STI-571, has been shown to decrease the density of tumor cells without causing inflammation or necrosis (21-23). Sunitinib is an oral multi-targeted tyrosine kinase inhibitor with activity against KIT, PDGFRs, VEGFRs, glial cell line-derived neurotrophic factor receptor, colonystimulating factor 1 receptor (CSF-1R) and FMS-like tyrosine kinase-3 receptor (FLT3) (24-29). Sunitinib appears to be an effective treatment for patients with imatinib-resistant/intolerant GISTs (7).

TKI-associated side effects mainly include nonhematological and hematological toxicities (30). TKI-associated side-effects affect the curative effect. Thus, the appro- 
priate management of TKI-associated side-effects is important. However, systematic research on the management of TKI-related toxicities remains scarce.

In conclusion, the complication of digestive tract hemorrhage in patients treated with sunitinib is rare. However, this case demonstrates that it does occur. Thus, we should be watchful of this complication in the clinic with sunitinib treatment. Its mechanism remains unclear, therefore data on molecular background, risk factors, treatment response and prognostic significance should be collected in a larger patient population and be further defined.

\section{References}

1. Hauber AB, Gonzalez JM, Coombs J, et al: Patient preferences for reducing toxicities of treatments for gastrointestinal stromal tumor (GIST). Patient Prefer Adherence 5: 307-314, 2011.

2. Di Scioscio V, Greco L, Pallotti MC, et al: Three cases of bone metastases in patients with gastrointestinal stromal tumors. Rare Tumors 3: e17, 2011.

3. Afuwape OO, Irabor DO and Ladipo JK: Gastrointestinal stromal tumour in Ibadan, Nigeria: a case report and review of current treatment. Afr Health Sci 11: 134-138, 2011.

4. Issar P, Dwivedi MK, Issar SK, Pal RK and Dewanagan L: Malignant gastrointestinal stromal tumours. Indian J Radiol Imaging 16: 65-67, 2006.

5. Wingen CB, Pauwels PA, Debiec-Rychter M, van Gemert WG, and Vos MC: Uterine gastrointestinal stromal tumours (GIST). Gynecol Oncol 97: 970-972, 2005.

6. DeMatteo RP, Lewis JJ, Leung D, et al: Two hundred gastrointestinal stromal tumors: recurrence patterns and prognostic factors for survival. Ann Surg 231: 51-58, 2000.

7. Chen YY,Yeh CN, Cheng CT, et al: Sunitinib for Taiwanese patients with gastrointestinal stromal tumor after imatinib treatment failure or intolerance. World J Gastroenterol 17: 2113-2119, 2011.

8. Kindblom LG, Remotti HE, Aldenborg F, et al: Gastrointestinal pacemaker cell tumor (GIPACT): gastrointestinal stromal tumors show phenotypic characteristics of the interstitial cells of Cajal. Am J Pathol 152: 1259-1269, 1998.

9. Hirota S, Isozaki K, Moriyama Y, et al: Gain-of-function mutations of c-kit in human gastrointestinal stromal tumors. Science 279: 577-580, 1998.

10. Demetri GD, von Mehren M, Blanke CD, et al: Efficacy and safety of imatinib mesylate in advanced gastronitestinal stromal tumors. N Engl J Med 347: 472-480, 2002.

11. Demetri GD, van Oosterom AT, Garrett CR, et al: Efficacy and safety of sunitinib in patients with advanced gastrointestinal stromal tumour after failure of imatinib: a randomised controlled trial. Lancet 368: 1329-1338, 2006.

12. Therasse P, Arbuck SG, Eisenhauer EA, et al: New guidelines to evaluate the response to treatment in solid tumors. J Natl Cancer Inst 92: 205-216, 2000.

13. Choi H,Charnsangavej C, Faria SC, et al: Correlation of computed tomography and positron emission tomography in patients with metastatic gastrointestinal stromal tumor treated at a single institution with imatinib mesylate: proposal of new computed tomography response criteria. J Clin Oncol 25: 1753-1759, 2007.
14. Miettinen $\mathrm{M}$ and Lasota J: Gastrointestinal stromal tumors: review on morphology, molecular pathology, prognosis, and differential diagnosis. Arch Pathol Lab Med 130: 1466-1478, 2006.

15. Daniels M, Lurkin I, Pauli R, Erbstösser E, et al: Spectrum of KIT/PDGFRA/BRAF mutations and Phosphatidylinositol-3Kinase pathway gene alterations in gastrointestinal stromal tumors (GIST). Cancer Lett 312: 43-54, 2011.

16. Miettinen $M$ and Lasota J: Gastrointestinal stromal tumors: pathology and prognosis at different sites. Semin Diagn Pathol 23: 70-83, 2006.

17. Corless CL, Fletcher JA, Heinrich MC, et al: Biology of gastrointestinal stromal tumors. J Clin Oncol 22: 3813-3825, 2004.

18. Bucher P, Villiger P, Egger JF, et al: Management of gastrointestinal stromal tumours: from diagnosis to treatment. Swiss Med Wkly 134: 145-153, 2004.

19. Annaberdyev S, Gibbons J and Hardacre JM: Dramatic response of a gastrointestinal stromal tumour to neoadjuvant imatinib therapy. World J Surg Oncol 7: 30, 2009.

20. Dematteo RP, Ballman KV, Antonescu CR, et al: Adjuvant imatinib mesylate after resection of localised, primary gastrointestinal stromal tumour: a randomised, double-blind, placebo-controlled trial. Lancet 373: 1097-104, 2009.

21. Ibrahim HH, Ahmad MS, Eskaf WA, et al: Malignant gastrointestinal stromal tumor of the tongue: case report and review of the literature. Oral Surg Oral Med Oral Pathol Oral Radiol Endod 111: e24-e29, 2011.

22. Nowain A, Bhakta H, Pais S, et al: Gastrointestinal stromal tumors: clinical profile, pathogenesis,treatment strategies and prognosis. J Gastroenterol Hepatol 20: 818-824, 2005.

23. Arru JM and Richardson JD: Gastrointestinal stromal tumors: pathogenesis and current treatment. J Ky Med Assoc 103: 211-215, 2005.

24. Osusky KL, Hallahan DE, Fu A, et al: The receptor tyrosine kinase inhibitor SU11248 impedes endothelial cell migration, tubule formation, and blood vessel formation in vivo, but has little effect on existing tumor vessels. Angiogenesis 7: 225-233, 2004.

25. Abrams TJ, Lee LB, Murray LJ, et al: SU11248 inhibits KIT and platelet-derived growth factor receptor beta in preclinical models of human small cell lung cancer. Mol Cancer Ther 2: 471-478, 2003.

26. Mendel DB, Laird AD, Xin X, et al: In vivo antitumor activity of SU11248, a novel tyrosine kinase inhibitor targeting vascular endothelial growth factor and platelet-derived growth factor receptors: determination of a pharmacokinetic/pharmacodynamic relationship. Clin Cancer Res 9: 327-337, 2003.

27. Murray LJ, Abrams TJ, Long KR, et al: SU11248 inhibits tumor growth and CSF-1R-dependent osteolysis in an experimental breast cancer bone metastasis model. Clin Exp Metastasis 20: 757-766, 2003.

28. O'Farrell AM, Abrams TJ, Yuen HA, et al: SU11248 is a novel FLT3 tyrosine kinase inhibitor with potent activity in vitro and in vivo. Blood 101: 3597-3605, 2003.

29. Schueneman AJ, Himmelfarb E, Geng L, et al: SU11248 maintenance therapy prevents tumor regrowth after fractionated irradiation of murine tumor models. Cancer Res 63: 4009-4016, 2003.

30. Joensuu H, Trent JC and Reichardt P: Practical management of tyrosine kinase inhibitor-associated side effects in GIST. Cancer Treat Rev Feb 37: 75-88, 2011. 